\title{
A prospective cohort analysis of COVID-19 positive and negative patients admitted to a single centre in the north-east of England during the peak of a pandemic
}

\author{
Authors: Anjan Dhar, ${ }^{A}$ Alexander Newman, ${ }^{B}$ Keryn Hall, ${ }^{C}$ Christopher Pexton, ${ }^{A}$ Satyasheel Ramful, ${ }^{A}$ Alison Carter, ${ }^{A}$ \\ Whajong Lee, ${ }^{A}$ Sarath Bethapudi, ${ }^{A}$ Anthony Allan, ${ }^{A}$ Safwan Akram $^{B}$ and Vikki Rand ${ }^{B}$
}

\section{Objective}

To investigate clinical, haematological, radiological and biochemical factors associated with outcomes in COVID-19 positive patients at Darlington Memorial Hospital (DMH) in the north-east of England (NEE).

\section{Methods}

A total of 275 patients admitted with either fever and/or respiratory symptoms over a 3 -week period from 26 March 2020 - 12 April 2020, during the peak of the COVID-19 pandemic were included.

\section{Results}

The mortality rate of patients at $\mathrm{DMH}$ was higher than the UK-wide data; $30.8 \%$ vs $26 \%$ respectively. COVID- 19 positive patients had a median age of 70 years, a higher proportion of males and more comorbidities (type 2 diabetes and hypertension), but they were not associated with adverse outcome. A higher number of obese patients with a BMI $>30$ (DMH 60.8\% vs UK 10.5\%, p <0.001) were found, but not associated with worse clinical outcome. Multivariate survival analysis identified four independent factors associated with worse outcome from COVID-19 infection in the DMH cohort: high frailty score $(5)$, low platelets $(100 \times 109 / \mathrm{L})$, lowest oxygenation levels $\left(\mathrm{SpO}_{2}<93 \%\right)$ and an immunocompromised status.

\section{Conclusions}

This study shows COVID-19 patients at DMH had a higher mortality rate than the UK national statistics. The independent risk factors identified in our study differed from national and international data. This analysis demonstrates the importance of understanding the variability of risk profiling in different regions of the UK.

\section{Conflicts of interest}

None declared.

Authors: ${ }^{A}$ County Durham and Darlington NHS Foundation Trust, UK; ${ }^{\text {BS }}$ chool of Health and Life Sciences, Middlesbrough, UK;

${ }^{\mathrm{C}}$ Darlington Memorial Hospital, Darlington, UK 